\title{
THE STRATEGY FOR ORGANIZED TECHNOLOGY IN THE LIGHT OF HARD-, SOFT-, AND ORG-WARE INTERACTION
}

Gennady M. Dobrov

International Institute for Applied Systems Analysis, Laxenburg, Austria

RR-83-2

January 1983

Reprinted from Long Range Planning, volume 12 number 4 (1979)

INTERNATIONAL INSTITUTE FOR APPLIED SYSTEMS ANALYSIS

Laxenburg, Austria 
Research Reports, which record research conducted at IIASA, are independently reviewed before publication. However, the views and opinions they express are not necessarily those of the Institute or the National Member Organizations that support it.

Reprinted with permission from Long Range Planning. The Journal of the Society for Long Range Planning and of the European Planning Federation 12(4):79-90.

Copyright (๑) 1979 by Pergamon Press Ltd.

All rights reserved. No part of this publication may be reproduced or transmitted in any form or by any means, electronic or mechanical, including photocopy, recording, or any information storage or retrieval system, without permission in writing from the copyright holder. 


\section{FOREWORD}

Dr. Gennady Dobrov was a visiting scientist in the Management and Technology Area of the International Institute for Applied Systems Analysis (IIASA) from October 1976 to the end of March 1979. It was, reputedly, a stimulating period under the direction of my predecessor, Professor Rolfe Tomlinson - now of the University of Warwick in the UK.

Dr. Dobrov's article reflects his own special interests, expertise, and experience in studies of organizational problems. It was a matter for regret that Dr. Dobrov was unable to stay longer at IIASA than he did, so as to pursue his researches further in this field.

ALEC M. LEE

Chairman

Management and Technology Area 


\title{
The Strategy for Organized Technology in the light of Hard-, Soft-, and Org-ware Interaction
}

\author{
Gennady M. Dobrov*
}

The construction of 'Orgware' as a component of technological systems is discussed. The trends in technological changes from conventional organized technology towards advanced-systems-integrated organized technology are shown. Evidence of Hardware, Software and Orgware interactions and their role in future sciencetechnological progress are demonstrated.

\section{Identification of the Problem}

Once it was said 'On the flag of contemporary science there should be written in capital letters the word 'ORGANIZATION". ${ }^{1}$ We have yet more reasons to say the same about 'technology'.

'Technology' is a word which is used very frequently now. But it is accepted and understood differently in cross-cultural contexts. In Anglo-Saxon tradition it is very common to understand it as 'applied science' or 'technical means' in which applied knowledge is embodied. If one follows Russian and German engineering traditions this term is often used in the sense of a way of realizing some possibilities or rather, more narrowly, as 'an engineering process'. Meanwhile there exists the contemporary international trend towards the extended notion of 'technology as the system by which a society provides for itself...' (see Webster ${ }^{2}$ for examples).

For designation of this systems-understood object of study and management, the idea of 'organized technology' became popular from the end of the 1960s. In

*The author is at the International Institute for Applied Systems Analysis, Schloss, Laxenburg, Austria. the preface of the four-volume anthology Science Management of Organized Technology its editors write 'There is no small amount of truth in their choice of terms. The articles which follow, however, stress the latest and most rigorous concepts and techniques available for $\mathrm{R} \& \mathrm{D}$ management ${ }^{3}$ (see page 12).

Practical experience gained in the course of time and recent theoretical findings have helped us to understand the problem more fully. Now within the systems framework, the identification of organized TECHNOLOGY has some facets which complement each other and which should be taken into account especially regarding management of technological changes and impacts:

(a) A system consisting of a set of technical means, methods and procedures to use them effectively, and organizational arrangements to provide the utilization of the human skills and interaction of this system with other ones;

(b) A man-made environment, that is the result of the implementation of knowledge, which permanently changes the amount and structure of the available resources, possibilities and constraints;

(c) A process of organized activity and a holistic object of social management at different levels of decision making.

\section{The Demands of Strategy}

Increasing demands for efficiency and effectiveness of technological development have made strategical orientation of techno-policy a vital necessity for any country of the world, regardless of the levels of development and acuteness with which they have recognized the finite character of all other resources for progress. 


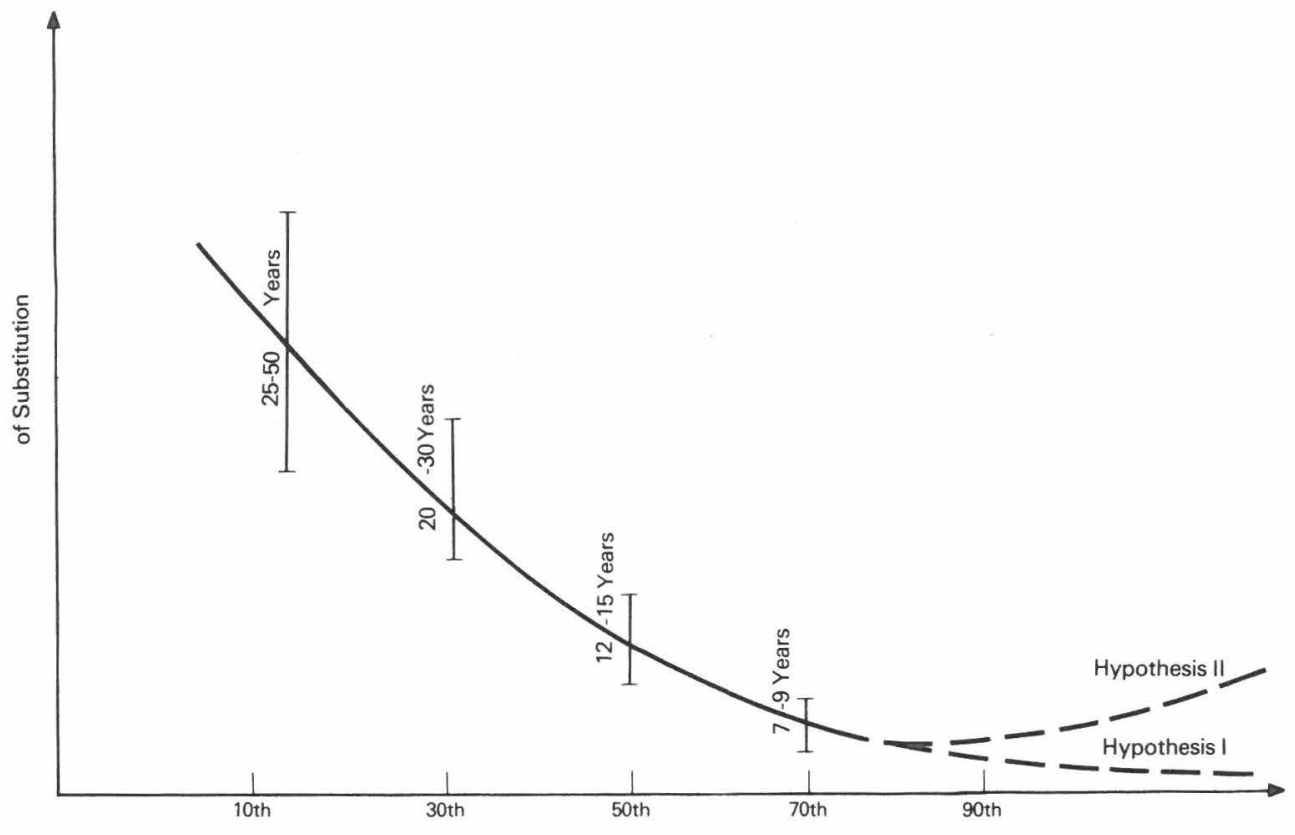

$T$, Years of 20th Century

Figure 1. Trends in the time of technology substitution

There are several circumstances which cspccially necessitate the systems-analytic approach to futurcoriented policy making for technological changes. The most important of them are:

(i) The rapidly growing role of science and its technical applications to the solution of a broad spectrum of problems disturbing contemporary society; this circumstance is shaped by the regular process of transforming practically applied scicntific knowledge into direct productive power and social capabilities;

(ii) The growing complexity of newly created technological systems, the diversity of their forms, and the intensification of their ties with other systems; this circumstance determines the character and dynamic structure of the positive and negative consequences of the functioning of technological systems;

(iii) There is an important regularity of technological changes-the permanent growth of 'science capacity'. More research and experimental efforts are required for creating new generations of technology and designing and manufacturing new products. The amount of material and intellectual resources allotted to technological development doubles in volume approximately every decade; in no country, however, has this process been accompanied by a corresponding rate of growth of the efficiency with which these resources are used.

(iv) The speed of technological changes and substitutions of technology generations is growing so that during our century (sce Figure 1) the time-pcriod for changes is reduced by half about every 20 years. In the main part of this period (for many engineering fields) the strategic ratio was:

$$
\frac{\mathrm{d} S}{S \mathrm{~d} t}>\frac{\mathrm{d} T}{T \mathrm{~d} t}>\frac{\mathrm{d} P}{P \mathrm{~d} t} .
$$

This ratio indicates the relative speeds of growth for the following indicators: production $(P)$, technology $(T)$ and science activity $(S)$.

It is obvious that both for different countries and for various problem areas, especially during various stages of development, this ratio has to be properly defined from the viewpoint of future oriented ST policy. No simple and easy extrapolations regarding these trends are possible. The world faces new problems: We should pay more attention to the new quality of technological systems-world wide and long-range effectiveness of technological options. It seems to me that this is a main dimension to the problem of Appropriate Technology which is being greatly discussed at the moment. We can stress the point if we try to reformulate the recently coined idea of 'small is beautiful', ${ }^{4}$ Our perception of what is 'small' or 'big' or how beneficial it is changes over the course of time. But it is certain that long-range effective options are beautiful indeed.

The need of analytically based and future-oriented management for society-organized technology is recognized by both developed and developing countries. 


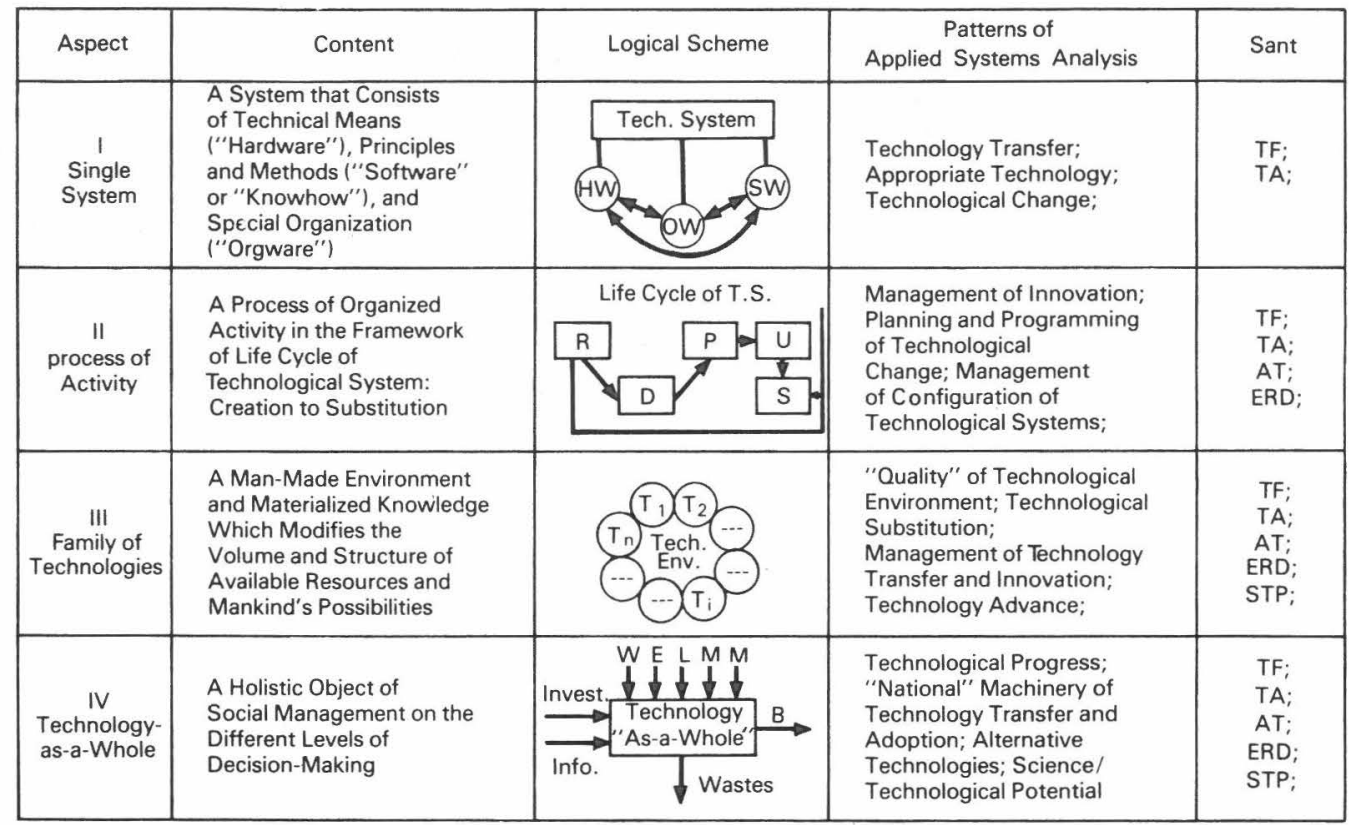

Figure 2. Main aspects of organized technology

During the last $10-15$ years, within the framework of science and technology policy studies and within the various branches of systems analysis, new types of research have emerged-'technology forecasting' (TF), 'technology assessment' (TA) 'altcrnative technologies' (AT), 'evaluation of R \& D' (ERD), and 'science/technology potential indicators' (STP) (to mention just a f(w).

These analytical efforts belong to the general rubric of applied systems analysis which may be called 'Systems Assessment of New Technology' (SANT). ${ }^{5}$ The object of SANT is again organized technology.

\section{The Structure of the Problem}

On the basis of a critical review of world experience of applicd systems studies of organized technology options, the next four hierarchical levels (or aspects) of this analysis could be identified (see Figure 2).

Later on we will discuss the first aspect of the problem more thoroughly. At this point we would like to present a brief commentary on all of them.

(a) Technology as a Single System: Basic Components Experience gained during the last decade has made it clear that, as a rule, it is not enough to have only a set of technical means [Hardware (HW)] or even knowledge and skill [Software (SW)]. They have to be supplemented by special organizational (in more general terms, socio-economical) innovations. To prove the point we can recall lessons learned from many science and technological 'shocks' or national and international difficultics in technology transfer.

To achieve success in putting each modern technological system into operation a specially designed organization is of great importance. This organization has to provide the necessary conditions for the utilization of decisionmakers' skills and the interaction of this system with other systems of different natures. We named this system Orgware. ${ }^{6}$

On the macro level ORGWARE comprises (Figurc 3) a set of economic and legal regulations (a system of prices, taxes, stimuli and constraints). On the operative level ORGWARE includes organization-structural solutions, procedures for management, training of manpower, maintenance service and special ways of interacting with other systems. The effective utilization of potential of any new technology demands appropriate Orgware (OW).

Three main dimensions of organized technology are shown in Figure 4.

\section{(b) Life Cycle of Technology}

This cycle comprises different kinds of activity: research, experimental development, plant and market introduction, diffusion, utilization and substitution of technological systems.

The practice of technological change knows many contradictions among these activities, for example the time and cost of the R \& D parts of the technology life-cycle enlarges so that during the most recent 5-7 


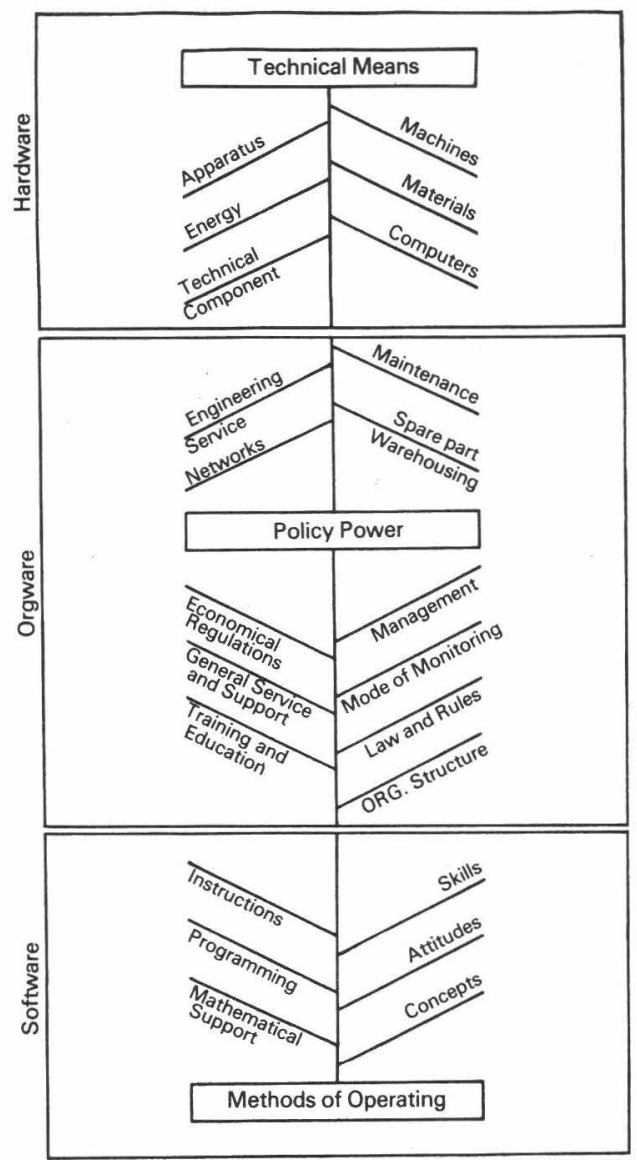

Figure 3. Structural tree of organized technology

years, the statistically estimated length of projects increased by $1.3-1.5$ times and their cost-more than twice. The time spent on decision making in organizational management also tends towards growth. Known data, together with our observations, show that the summary time of waiting for managerial decisions can exceed the general duration of all other actions of the life cycle.

Nationally supported technology transfer-the active patent and licence policy, international cooperation and technology exchange-are important for all countries as an effective option for the above-mentioned constraints. There is data that if all available ST information is utilized, it would mean at least a redoubling of efforts in research, development and technological innovations. Technologically developed countries also have useful experience in solving problems in other ways: MBO (Management by Objectives), PPBS (Planning, Programming, Budgeting System), Selection of Portfolio R \& D Ideas, Technological Program Risk Evaluation, etc.

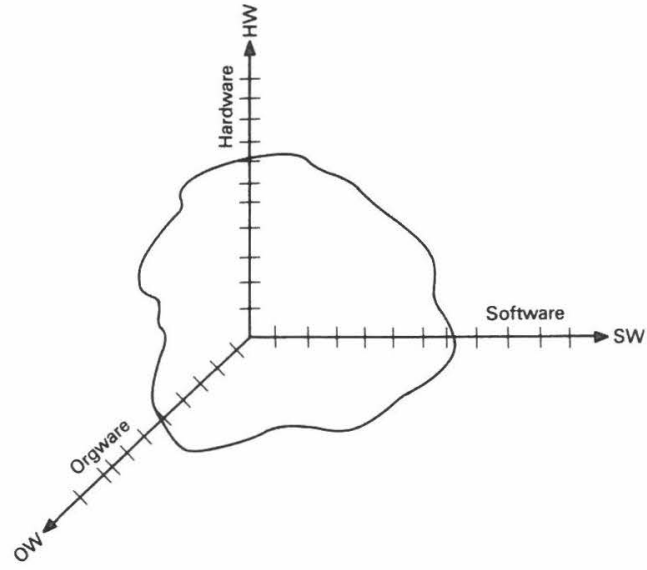

Figure 4. The space of components of organized technology

The U.S.S.R. has experience of long-range and operative planning of $\mathrm{R} \& \mathrm{D}$ and goal-oriented programs of technological advancement where managerial efficiency is increased by applying the set of systems demands'speed up', 'wide spread' and 'complete' utilization of available final and intermediate $\mathrm{R} \& \mathrm{D}$ results. The main benefits of this approach are: increasing the quality of technological options, reduction of time for innovation period by $1.5-1.8$ times, and the diminution of the volume of non-applied results by $4-5$ times.

(c) The Technological Environment: a Structural Change This aspect of organized technology is to a considerable extent similar to the systems approach adopted in ecology. Water, land, air, etc. are studied by specific sciences.* Each of those scientific disciplines has its own language, indicators and models, which very often happen to be incompatible. At the same time, a consideration of those elements within the framework of the theory of ecological systems and practical environment monitoring has been widely recognized.

Various 'families' of technologies have been created and are being used, as well as those that are being mastered at present, from a new kind of unity. This unity specifically interacts with nature and society. An applied systems analysis approach to a man-made technological environment is the only way to elaborate and put into operation such important concepts as a 'rate of technological substitution', 'quality of technological environment', 'a technological risk' and 'flexibility of a technological system'. It implies the capacity of the technological environment to accept new scientific and technological opportunities and to respond to changes of social, economic and ecological demands, etc., and also to those which will develop in the future.

-A comprehensive conception for this case was proposed in IIASA ${ }^{7}$ WELMM approach (Water, Energy, Land, Material, Manpower)-see Figure 2. 
There is a common understanding that an analytical method of policy design is an important final step for modern systems analysis. Many issues like natural resources, environment, energy complexes and agriproduction, human settlements and healthcare systems which are subjects where systems analysis is applied, can be reasonably explained only when long-range scientific and technological factors and socio-economic criteria related to these factors are taken into account. In fact, we are dealing with the relations between technology and the economy in any case of policy design for various fields of activity.

\section{(d) The Option of Technology As-a-Whole}

The systems concept of organized technology assumes that technology should also be studied as a holistic object of management. In this case, the management of technologies influences the activities and behaviour of individuals, groups and organizations by using the information, investment and available natural resources.

However, between the levels of technology and the final economic indices, only implicit connections exist through complicated social and economic mechanisms. The attempts to study this type of the model look encouraging only on the level of macro models which take into account the essential time-lag between 'input' and 'output'.

In the model developed in the Institute of Cybernetics $(\mathrm{Kiev})^{5,8,9}$ the following set of variables was used: the rate of growth of national income, the estimated economic growth of ST potential, the delay (in years) between inputs and outputs in the system, the timehorizon of projected decisions. For example, in Table 1 two variants of possible policies are given.

Table 1. This pattern is an illustration of the great potential of socio-organizations arrangements of technological changes

\begin{tabular}{lcccc}
\hline & $\begin{array}{c}\text { Time } \\
\text { Horizon }\end{array}$ & $\begin{array}{c}\text { National } \\
\text { Income } \\
\text { growth }\end{array}$ & $\begin{array}{c}\text { Time- } \\
\text { delay T, level of investment } \\
\text { (years) }\end{array}$ & $\begin{array}{c}\text { Final annual } \\
\text { in STP (rubles) }\end{array}$ \\
\hline Scenario I & $1960-1990$ & $\times 7$ & 9 & $76 \cdot 10^{9}$ \\
Scenario II & $1960-1990$ & $\times 7$ & 7 & $48 \cdot 10^{9}$ \\
\hline
\end{tabular}

\section{Orgware: Roots and Evidence}

The organizational framework for technological progress is one of the main problems of future technological changes. In many regions of the world, a number of very acute problems which have to be solved, demands that a policy design for new technologies should be reconsidered from the systems viewpoint. Some crucial problems are mentioned for various parts of the world. They are for example:

accelerated growth of labour productivity and diminishing the unemployment as a result of the wide use of new and appropriate technology; solving a complex food and agriculture problem on the basis of systems realization of new technologies;

is 'blue revolution' in environment and nature, expected in view of forthcoming technological opportunities;

is creation of a 'zero-waste' technology for the whole chain of productive processes, from discovering resources to the production of goods and utilization.

The experience gained, both through IIASA investigations and our previous scientific activities, strongly supports the idea that in cases when organizational and managerial aspects of systems technologies do not get proper consideration, the effect expected by society in solving exciting problems is not often achieved, in spite of the fact that considerable investment is made into the other two components of technology. At this point the following definition of ORGWARE should be suggested: a set of organizational arrangements specially designed and integrated using human, institutional, and technical factors to support appropriate interaction of the technology and external systems.*

Orgware should be designed as both problem-oriented and machine-oriented. There are also some wholesystem criteria: minimization of time-delays, optimal storage and use of information, etc. Intersystems criteria define the quality of a given system 'to be appropriate to the conditions of application'. They have to play a particularly important role in designing orgware as well as hardware and software. The development of models and methods for designing the Orgware as a systems element of new technologies will be one of the most acute problems for systems analysis of organized technology in the near future.

How has the role of Orgware emerged historically? Have its forms changed? Figure 5 displays an evolutionary sequence involving the concurrent development of a number of processes involved in the historical evolution of technological systems:

is Primary changes in technological substitutions (TS) of the human function (HF) in work;

is Change from manual to mechanization to automization work processes;

is Emerging new forms (increasingly sophisticated) of organizational arrangements (OW).

It is proposed that Orgware be an increasing social component of systems. This evolutionary picture, taken at a general level, leads us to the idea that there exists something which we may refer to in a sense as the 'Law of Orgware'.

$$
\mathrm{TS}>\mathrm{HF}>\mathrm{OW} \uparrow
$$

'The more technology substitutes for individual human

- Here I use some definitions from the paper prepared in IIASA together with M. McManus and A. Straszak. ${ }^{10}$ 


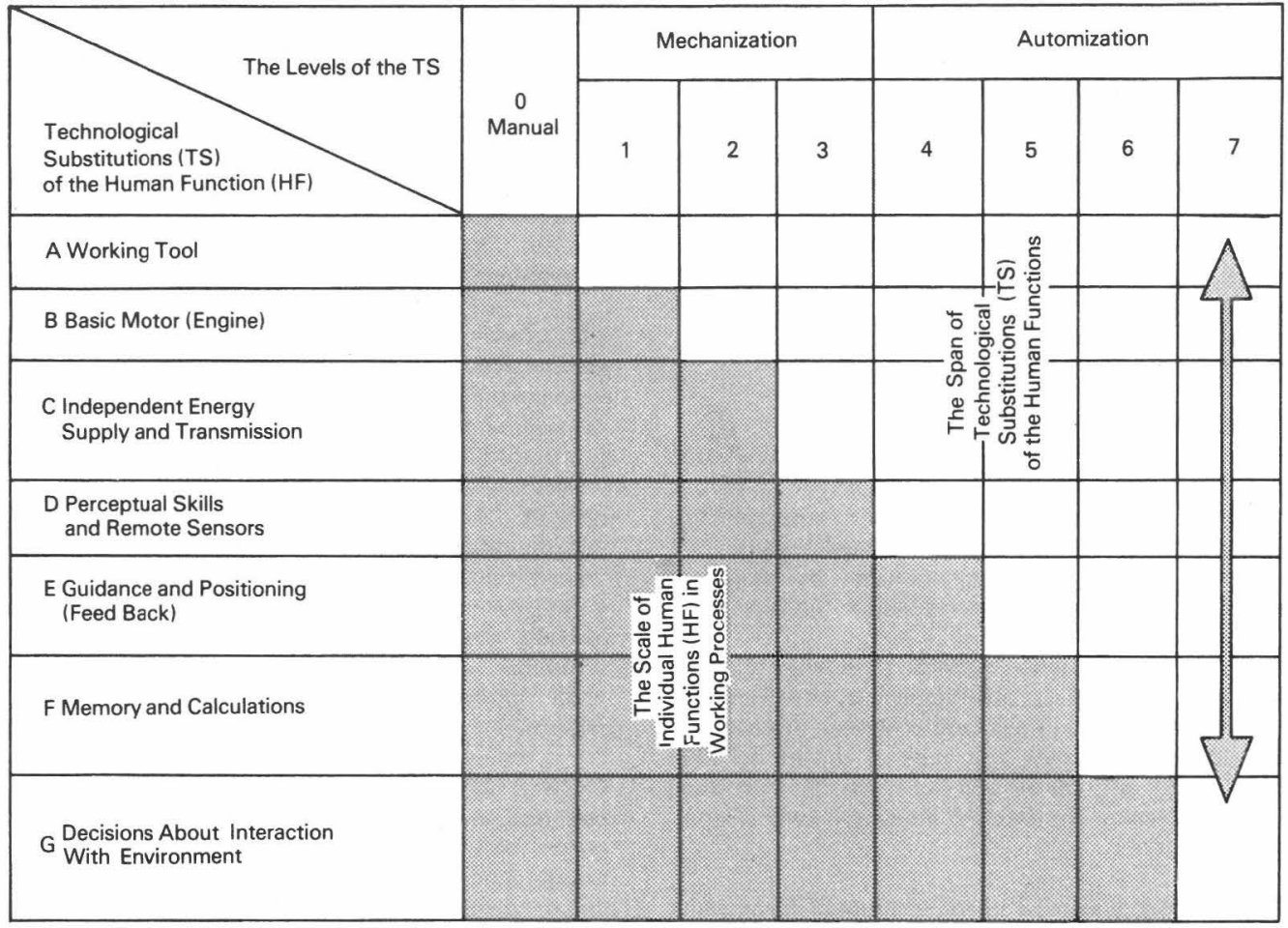

Figure 5a. The emergence of orgware

\begin{tabular}{|c|c|c|c|c|c|c|c|}
\hline \multirow[b]{2}{*}{$\begin{array}{l}\text { Examples for } \\
\text { Each Level } \\
\text { of Technological } \\
\text { Advance }\end{array}$} & \multicolumn{7}{|c|}{ Typical Elements of Orgware (OW): } \\
\hline & $\begin{array}{l}\text { Training and } \\
\text { Supervision }\end{array}$ & $\begin{array}{c}\text { Social } \\
\text { Regulations } \\
\text { Industrial } \\
\text { Organization }\end{array}$ & $\begin{array}{l}\text { General } \\
\text { Services and } \\
\text { Maintenance }\end{array}$ & $\begin{array}{l}\text { Special } \\
\text { Technical } \\
\text { Supply: } \\
\text { Operational } \\
\text { System }\end{array}$ & $\begin{array}{l}\text { Re-training; } \\
\text { Advanced } \\
\text { Engineering } \\
\text { Service }\end{array}$ & $\begin{array}{c}\text { Computer-based } \\
\text { Modes of } \\
\text { Monitoring; } \\
\text { Changed Org } \\
\text { Structures; } \\
\text { Networks }\end{array}$ & $\begin{array}{l}\text { Special Laws; New } \\
\text { Established Economic } \\
\text { Regulations; } \\
\text { Advanced Mgt. of } \\
\text { Socio- Technological } \\
\text { Systems }\end{array}$ \\
\hline $\begin{array}{l}\text { Machine Tool } \\
\text { Support }\end{array}$ & & & & & $\mathrm{TS}=\mathrm{HF}$ & $\Rightarrow$ ow $\hat{\uparrow}$ & \\
\hline $\begin{array}{c}\text { Steampowered } \\
\text { Engine }\end{array}$ & & & & & \multirow{2}{*}{\multicolumn{3}{|c|}{$\begin{array}{l}\text { w; The more Technology Substitutes } \\
\text { Individual Human Functions in work } \\
\text { Processes, the Greater Role of } \\
\text { Orgware as an Intrinsic Social } \\
\text { Component of Technological Systems }\end{array}$}} \\
\hline $\begin{array}{l}\text { Individually } \\
\text { Driven } \\
\text { Machinery; } \\
\text { Conveyors; }\end{array}$ & & & & & & & \\
\hline $\begin{array}{l}\text { Barometers; } \\
\text { Indicators }\end{array}$ & & & & & & & \\
\hline $\begin{array}{l}\text { Automatic } \\
\text { Control } \\
\text { Devices }\end{array}$ & & \multirow{2}{*}{$\begin{array}{r}\text { Scale of } \\
- \text { - Role of Org }\end{array}$} & Emerging & & & & \\
\hline $\begin{array}{l}\text { Programmable } \\
\text { Automatic } \\
\text { Machine } \\
\text { Tools }\end{array}$ & & & & & & & \\
\hline $\begin{array}{c}\text { Integrated } \\
\text { MIS } \\
\text { Management } \\
\text { Information } \\
\text { System }\end{array}$ & & & & & & & \\
\hline
\end{tabular}

Figure $5 \mathrm{~b}$. The emergence of orgware (cont'd) 
functions in work processes, the greater the role of Orgware as an intrinsic social component of technological systems.'

A common misunderstanding or illusion is that the human role in work processes is decreasing as mechanizand automation increase at the society level, however, we see that the human role changes its function or functional application vis-à-vis machines. Non-creative work processes at earlier stages involved forms of human activity which were characterized by higher degree of manual work that required more routine qualities. Work processes that required a more creative human role exist at higher levels of technological substitution.

In the studies of complex systems a recognition of the role of 'organization' is an important stage. For organized biological systems the term 'ORG' was proposed. ${ }^{11}$ Recently "ORG has been understood as a set of elements of a mixed nature which has, and operates by, internal information about aims, methods and resources of activity (compare 12 p. 85).

The history of technological advancement gives us examples of when success was achieved due to the fact that the special organizational arrangements were made within the system structure of technological options.

An older example is the assembly line and related to it socio-economical organizational arrangements in mechanical cnginecring. Now this kind of OW is substituted by so-called 'work islands' or 'cell-organization' of assembly processing.

As it was demonstrated by Volvo in Sweden ${ }^{13}$ and Fiat-Comau in Italy ${ }^{14}$ and the 'Silmont' system in Poland ${ }^{15}$ the concentration of work operations, new division and coordination of labour, and flexible consequences of interactions highly mechanized and automated equipment open the new 'non-line' way for more effective utilization of possibilities of industrial robots and machine-tools with digital programmed control. At the same time new possibilities for job enrichment and stimulation of a well educated and skilled generation of workers is important.

One of the more modest but also a classical pattern of orgware is the computers network. It is first of all the systems set of organizational, economical, legislative and managerial arrangements. The experience of countries and world regions where this option has succeeded has given evidence of the growing role of orgware as a powerful factor of socio-technological effectiveness.

World competition in electronic data-processing is now shifting from the quantity of computers towards the scale and level of performance of computer centers and networks.

Symbolic here are current trends towards the reallocation of the main portion of efforts (and investments) from $\mathrm{HW}$ to $\mathrm{SW}$ and recently also to $\mathrm{OW}$ within the general framework of a single systems option.

The common rule is known and can be repeated in some extended form: the more sophisticated and potentially effective a new technique is, the more urgently an appropriate orgware is needed.

\section{HW-SW-OW Interactions Toward a Systems-Integrated Organized Technology}

The historical path of mankind from homo-sapiens to homo-powcrful and homo-managing is the way of transformation of accepted and applied scientific knowledge into a more direct productive and social force of society.

Figure 6 depicts differing perceptions of the relative roles of technology, science and organization. Stage I shows a more primitive view of science $(S)$, technology $(T)$ and organization $(O)$ as separate realms of activity. Stage II suggests another view of technologically related developments and activity. On this level of interaction Hardware (HW) and Software (SW) are at least partly integrated, yet together remain essentially separated from the skill and the 'art' of organization and management.

These interacted components of technology-a set of technical means and a body of scientific knowledgeare called Hardware and Software. For these components the next definition could be proposed: HW is the knowledge and skills embodied in the different technical means as a materialized factor of the productive process. SW is science- and experience-based knowledge developed to the level to be directly used in operations related to productive process.

Stage III in Figure 6 shows the integration of HWSW-OW as a model for understanding organized technological systems. In computer science, for example, this kind of view is replacing earlier conceptions of data processing as only HW-SW interaction. Many experts have now begun to appreciate Orgware aspects as something which is not outside technology, but an essentially intrinsic component as well. In engineering fields this understanding leads to the conception of a technological system as a three-dimensional technological entity, every component of which has its own set of internal elements.

The range of possible elements in a given technological system can be quite extensive. Figures $7(a$ and b) illustrate some of them. Some classic examples of the hardware, software and internal structure of them are depicted. Of primary importance is the question of element interaction. What is the internal structure of an organized technological system? And how might we formulate a framework for in-depth analysis of 'advanced' technological systems?

Figure 7a depicts three components of a 'conventional' technological system with several specific elements in 


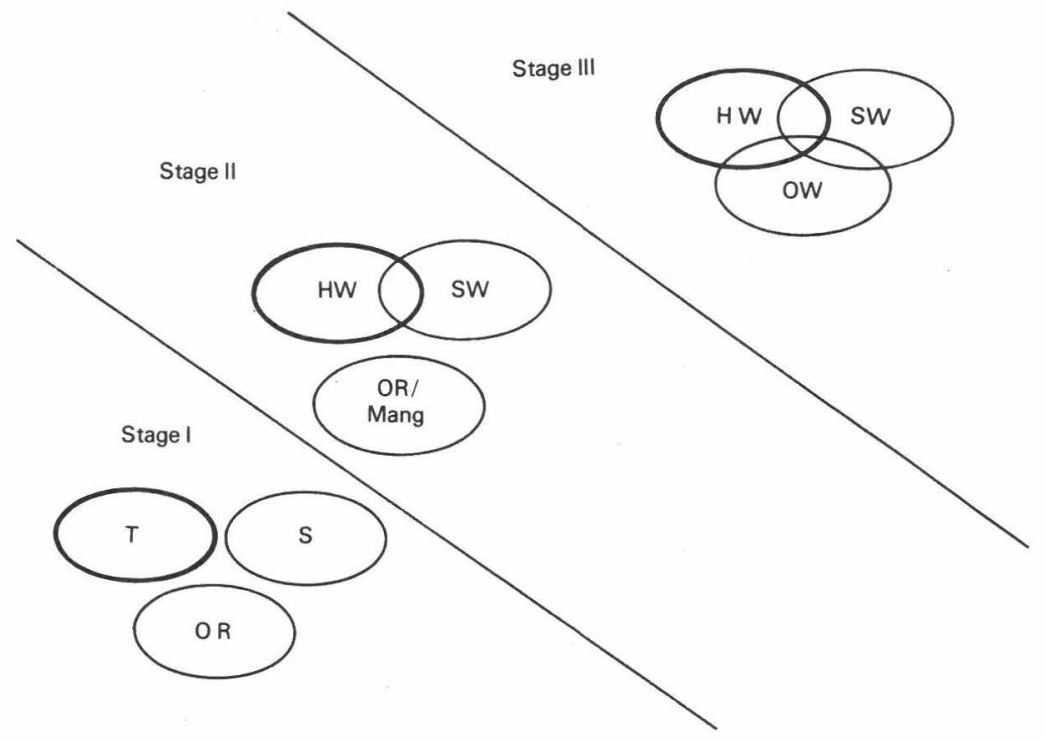

Figure 6.

each component. An important element of the hardware component, for example, is 'machinery and facilities'. An element in this example for the hardwareorgware sector is "engineering support for monitoring'. This element of interaction between the components of hardware and orgware is crucial to the system and, for a conventional type of an organized technological system, this element is quite common.

Figure $7 \mathrm{~b}$ shows the same system but with the addition of more elements from each, HW, SW, OW component and elements which are combined HW-SW, HW-OW and SW-OW integrated. These examples are ones which have been specially designed to interact in a mutually supporting manner. Unlike the simpler, conventional system, this system is more complex and has been more carefully designed with qualities of 'systems integration'. The construction of 'SystemsIntegrated Organized Technology' is thus appropriate for more advanced technological systems and is

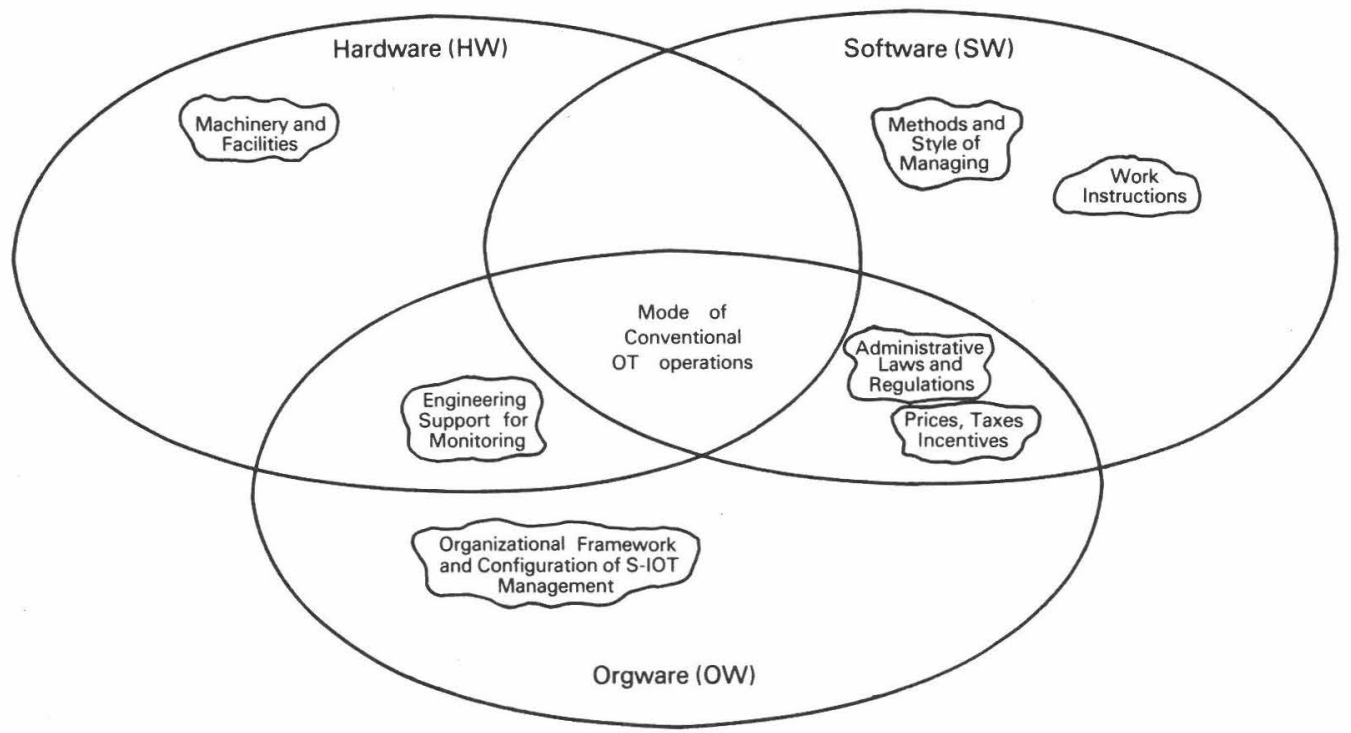

Figure 7(a) Hardware, software, orgware interactions towards the systems-integrated organized technology (S-IOT) 


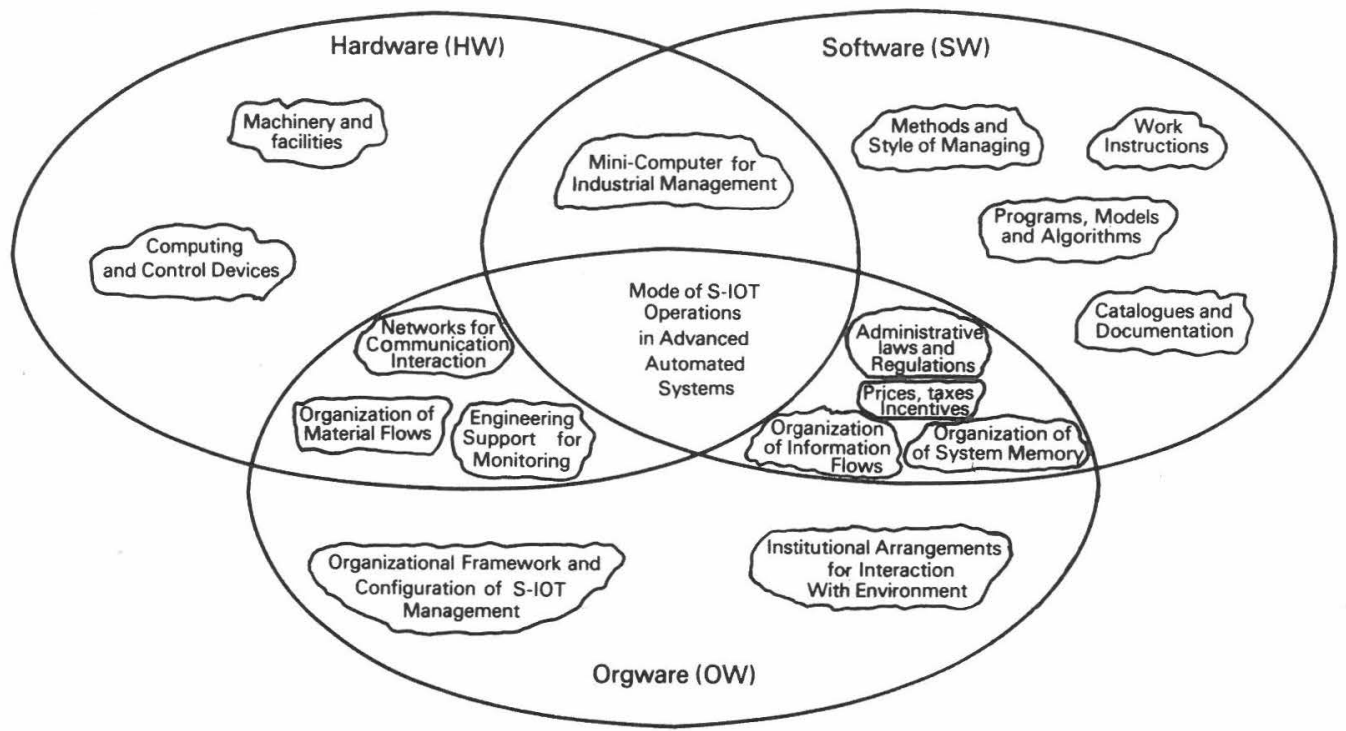

Figure $7(\mathrm{~b})$. Hardware, software, orgware interactions in systems-integrated organized technology (S-IOT)

defined broadly as follows: A technology option consisting of a comprehensive set of primary components (hardware, software, orgware), the mode of operation of which is characterized by mutually supporting elements, flexibly interacting to achieve a defined purpose.

The creation of S-IOT conditions is not an easy task. The construction suggests that we are dealing with advanced levels of system interaction. Figure $7 \mathrm{~b}$ includes, for example, advanced hardware elements (computing devices), advanced software (programs, algorithms, etc) and special orgware arrangements (organizational framework). Other elements include terminals and mini-computers, communication networks, flow design and even special arrangements relating to issues external to the system, i.e. prices, taxes, incentives. At the center of this diagram are the system elements which ultimately involve the interaction of hardware, software and orgware technological components. These elements, products of the three-way interaction, require an advanced level of design planning, decision making and coordination in the system and as such are the products and essential elements of a 'S-IOT' system.

Not only are the elements comprehensive and advanced, but also they are carefully designed and put together so as to be mutually supportive and flexible to integrated system functioning and overall system cohesiveness. These system qualities are seen as facilitative to the overall accomplishment of a system's technological function or purpose.

An example, in fact, of S-IOT system design is the CAITR project developed within IIASA. ${ }^{16}$ CAITR (Computer Assisted International Team Research) is a system, an organized technological option, for use in international team research. The CAITR system to be used in IIASA's cooperative research activities pools hardware, software and orgware elements together in a specially designed mode of operation. CAITR exemplifies an advanced system; specially designed, it has more than just hardware-software system characteristics. In fact, the orgware component of CAITR is a crucial one and needs special emphasis in the early phases of CAITR.

More widely known patterns of S-IOT are contemporary computer-based management/informational systems for the monitoring of a productive process in its all socio-technological dimensions. One type of them called Flexible Manufacturing Systems ${ }^{17}$ is a class of computer-aided manufacturing systems having multiple work stations, direct numerical control (DNC), automated material handling, and system control by computer with appropriate algorithms. Another one is called the Integrated Systems of Management. ${ }^{18}$ It emphasizes the unity of automated control of productive processes and computer-based management of industrial organization.

\section{The Future-Long-Range Effective and Appropriate Technology} Advancement

One important regularity stems from world experience: HW-SW-OW interaction leads to the formation of organized technology and further progress in developing any modern organized technological system is conducted towards the creation of a more advanced system called the Systems-Integrated Organized Technology. 
Table 2. Levels of Technological Development

\begin{tabular}{|c|c|c|c|}
\hline No. & Standard UN terms & Main features of technology implementation for development & Conventional term \\
\hline 1. & Initial & Practically no technology (of that kind) used in the region & Mainly manual work \\
\hline $\mathrm{T1}$ & & Transitional level I-from initial to basic & \\
\hline 2. & Basic & $\begin{array}{l}\text { There are some cases of technology implementation but without } \\
\text { much impact on regional development. SW is being transferred } \\
\text { through a few practical patterns }\end{array}$ & $\begin{array}{l}\text { Intermediate technology } \\
\text { for adaptation }\end{array}$ \\
\hline $\mathrm{T} 2$ & & Transitional level II-from basic to operational & \\
\hline 3. & Operational & $\begin{array}{l}\text { Extensive implementation of different types of machines. Fast } \\
\text { growth in the understanding of the economic role of technology. } \\
\text { Regular forms of professional teaching and dissemination of SW } \\
\text { information. First experience in developing appropriate OW }\end{array}$ & Broad mechanization \\
\hline T3 & & Transitional level III-from operational to advanced & \\
\hline 4. & Advanced & $\begin{array}{l}\text { Extensive market penetration and intensive use of systems } \\
\text { machines and automization. Deep understanding of social role and } \\
\text { constraints of 'technologization'. Development and regular } \\
\text { implementation of appropriate form of HW, SW, and OW }\end{array}$ & $\begin{array}{l}\text { Advanced technological } \\
\text { systems }\end{array}$ \\
\hline
\end{tabular}

A process of technological growth ('technologization') for any sectors of production and different regions can be scaled on definite levels. This makes the assessment and comparison of different patterns possible. The United Nations has one type of standard definition of technological development levels ${ }^{19}$ which has successfully been used for studying such specific cases of technologization as computerization. ${ }^{20}$ Table 2 presents my generalization based on this experience.

Some ideas about strategy for technological policy are known from the practice of design-making in different countries and have been vigorously discussed in the science management literature. The typical patterns of them are: 'small is beautiful' or vice versa-'the more, the bigger, the better'. Other strategical orientations have been proposed by systems analysis, one of them suggests the development of 'Labor Oriented' technology or vice versa: calls one to look for ways of maintaining appropriate efficiency of technological systems in spite of constraints on the rate of growth of cost and frequency of changes-i.e. to maintain 'longrange efficiency' ${ }^{21}$

The wise choice and analytically substantiated definition of strategical alternatives appropriate for a given region are vitally important for success or failure of technological policy to meet future demands. The study of strategy for organized technology has to be an organic part of any sectoral policy design. We will demonstrate the methodological value of the conception of HWSW-OW interaction on the pattern of IIASA's experience related to its Food and Agriculture Program (FAP). Agricultural systems as a whole are only at an early stage of participation in the main stream of the contemporary science-technological revolution. This is especially true for the technological part of the agrisystem. The well-known patterns of the "green revolution' succeeded without essential in-depth changes in technical means and technological policy. But nowadays it becomes more and more clear that we are close to a new turnover point regarding technology as one of the leading actors on the scene of different productive sectors. ${ }^{22}$

This historical challenge will be explained with reference to the standard description of the levels of technological development of countries-from 'initial' to 'advanced'. From the point of view of technological development, world agriculture is on the 'operational' level, while developing countries are in transit from the 'basic' level and developed ones to 'advanced'.

The main challenge of our era could be discussed with the help of Figure 8. Here 'levels' of technological development are arranged on the time-axis while the other axis represents the relative rates of growth of productivity of agricultural labour and capital capacity of agri-technological systems (cost of technology per unit of agri-output). Here the level of the beginning of the 'operational' phase of technological development $(\sim 50$ years ago $)$ has been taken for 1 .

As shown (Figure 8) this 'scenario' for the future is characterized by a further increase in agricultural labour productivity and a decrease in capital-capacity of technological policy. For different countries and various agri-technological areas the new situation can be predicted for different time-horizons. This analysis would be a logical continuation of the study of capitalintensive and labour-intensive components of technological policy. It seems reasonable to expect that essentially different results of calculations in macroeconomical modelling would be obtained by using new data related to the technological part of this policy. 


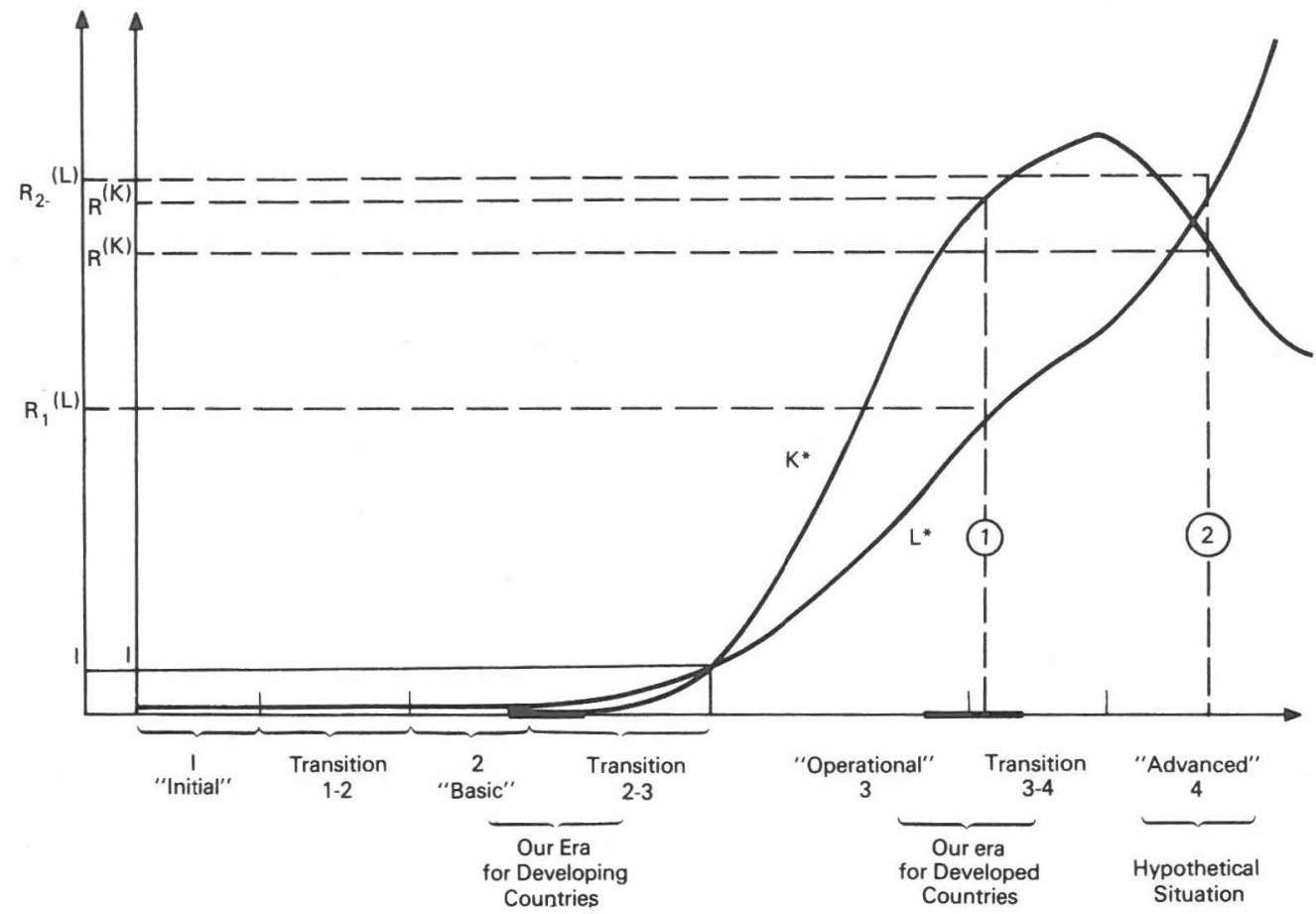

Figure 8 . Trends in labour-productivity $\left(\mathrm{L}^{*}\right)^{*}$ and capital-capacity per unit of output $\left(\mathrm{K}^{*}\right)$

What kind of factor will have a decisive influence on the foreseeable crucial changes? The hypothetical situation (see Figure 8) can be understood only as a system-effect of some current trends and future events. Among them the following can be identified for our case-study:

(i) Accumulated technical potential of industry and an achieved high level of 'technologization' of agricultural production that will make possible the development and acceptance of essentially new advanced 'Hardware' for agri-technology.

(ii) Accumulated biological potential of land, broad use of reliable technological options embodying new principles of 'few operational' processing, a combination of ideas from mechanics and electronics with chemical and biological ones, progress in machine-oriented changes of the plants to be processed: all that will serve as a base for advanced 'Software' of new agri-technology.

(iii) Accumulated organization/management experience, creation of new appropriate forms for supporting and monitoring agricultural systems with an active role of socio-economical incentives, laws and regulations oriented toward strengthening the stimulus and participation of agri-producers in agri-technological policy making: all that can serve as a base for advanced 'Orgware' of new agri-technology. (iv) Accumulated world experience in agri-technological policy and in the systems-analytically substantiated process of decision-making here can serve as one of the crucially important additional 'Resource' for agri-development besides the increasing financial support and wise utilization of natural resources.

Well documented practice and evidences appearing in current management publications, some trends in economical statistics and theoretical construction of organized technology lead to the understanding of the set of main 'bottlenecks' or 'shortcomings' (typical for many countries) in managerial decisions related to technological policy-making.

Some demands to improve the Management of Technological Innovations related to such 'bottlenecks' and 'shortcomings' can be identified as follows (see Figure 9):

(A) 'Comprehensiveness.' Lack of comprehensiveness in the initial aims and directions of policy-making usually occurs as a one-sided emphasis on machines (the 'hard' part of technology) with underestimation of the importance of developing new knowhow ('software') and of creating an appropriate organizational and socio-economic infrastructure ('orgware'); 


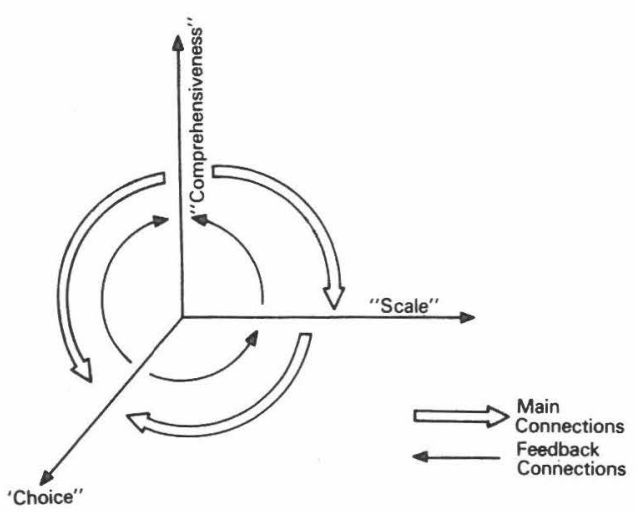

Figure 9. Interconnections among the three applied managerial problems.

(B) 'Scale'. A wrong definition of the scale of appropriate technology options ('small', 'big' or 'intermediate' and their 'mix') usually leads not only to current mistakes in allocation of resources and efforts but also to delayed and diminished possibilities of reaching strategically important changes in the technological situation;

(C) 'Choice'. A random (non-rational) choice of the assortment of specific technical means from among those available on the market or expected in the near future leads to low efficiency of current efforts and wrong directions of future technological substitutions.

These basic managerial questions ('A', 'B', 'C') of technological policy overlap different levels of decisionmaking. It could be shown as below:

Table 3.

\begin{tabular}{l|lll}
\hline National level of decision making & A & & \\
& & B & \\
Producers' level of decision making & & & C \\
\hline
\end{tabular}

The development of practical applicable methods and models for substantiation of managerial decisions related to 'comprehensiveness', 'scale' and 'choice' is among the first rank aims of systems analysis applied to technological options. Other crucially important demands such as 'adaptivity', 'risk', etc. are not the subject of this paper.

Taken as a whole the solution of these practical problems of management could compose a main set of conditions for the development of organized technology in a given country towards Systems-Integrated Or- ganized Technology. This kind of technological policy should be appropriate to the great hopes of mankind for wisely directed science-technological advancement.

\section{References}

(1) P. L. Kapitsa, Cit. Alan L. Mackay, The Harvest of Quiet Eye, The Institute of Physics, Bristol and London (1977).

(2) Webster's New World Dictionary of the American Language, 2nd Edn, p. 1460 (1976).

(3) Marvin J. Cetron and Joel D. Goldhar, (Eds.), The Science of Managing Organized Technology, Vols 1-4, Gordon and Breach (1970).

(4)F. F. Schumacher, Small is Beautiful, A Study of Economics as if People Mattered, Blound and Briggs, London (1973).

(5) G. M. Dobrov, Systems assessment of new technology in decision-making in government and industry. IIASA Working Paper,WP-77-8, (June 1977). To be published in Technology Forecasting and Social Change (1978).

(6) G. M. Dobrov, Why management must catch up with technology, International Management, 32 (VII), 76-80. November (1977).

(7) M. Grenon and B. Lapillonne, WELMM Approach to Energy Strategies and Options, IIASA, RR-76-19, December (1976).

(8) V. N. Klimenjuk, Management of Science Potential Development and Utilization, Ed. G. M. Dobrov, Kiev, Naukova Dumka (1974). (Russian.)

(9) B. Ja. Brusilovski, Mathematical Mode/s for Prognostic and Organization of Science, Eds. G. M. Dobrov and V. V. Ivanov, Kiev, Naukova Dumka (1975). (Russian).

(10) G. Dobrov, M. McManus and A. Straszak, Toward systemsintegrated organized technology, IIASA, March (1978). (Manuscript to be published.)

(11) R. W. Gerard, Units and concepts of biology, in Modern Systems Research for Behavioural Scientists, p. 53, Chicago (1968).

(12) T. Scibor-Rylska, The Order and Organization in the Nature, Pax, Warszawa (1974) (Polish.)

(13) P. Gyllenhammer, People at Work, London (1977).

(14) A. Bennet and T. Schoeters, Technical page, Financial Times, p. 13, 1 November (1977).

(15) J. Ruranski, Komputer natasme (Computer on the line) "Zycie i Nowoczesnosc" (Warsawa) N 414, pp. 1, 4, 27 April (1978)

(16) G. M. Dobrov, R. H. Randolph and W. D. Rauch, Informational networks for international team research, IIASA, Manuscript of April (1978). (To be published.)

(17) Pugh Hickson, Pheysey, Operations technology and organization structure: an empirical appraisal, Administrative Science Quarterly, Vol. 14, N3, September (1969).

(18) V. M. Glaushkov, Introduction in management information systems, Technika, Kiev (1972).

(19) United Nations, Application of computer technology for development, Department of Economics UN, ST/ECA/136, (1971). R. Barquin, A categorization of the Latin american nations according to their potential for development of a computer industry, Working Paper of Sloan School of Management, MIT, WP 678-73, October (1973).

(20) P. Buringh and $H$. van Heemst, An estimation of world food production based on labour-oriented agriculture, Wageningen, The Netherlands, August (1977).

(21) G. Dobrov, A strategy for organized technology. Paper delivered at IIASA Workshop 'Systems Assessment of New Technology: International Perspectives', Laxenburg, July (1977). To be published in Technology Forecasting and Social Change (1978).

(22) V. Mouchnik, E. Holland, Some peculiarities of contemporary stage of technological development, (Russian), in Science Technology Advance, 'Nauka', Novosibirsk (1976). 